\title{
Recovery from DNA replicational stress is the essential function of the S-phase checkpoint pathway
}

\author{
Brian A. Desany, Annette A. Alcasabas, Jeffrey B. Bachant, and Stephen J. Elledge \\ Verna and M arrs M cLean Department of Biochemistry, Howard Hughes M edical Institute, Baylor College of M edicine, \\ Houston, Texas 77030 USA
}

\begin{abstract}
RAD 53 and MEC 1 are essential genes required for the transcriptional and cell cycle responses to DNA damage and DNA replication blocks. We have examined the essential function of these genes and found that their lethality but not their checkpoint defects can be suppressed by increased expression of genes encoding ribonucleotide reductase. Analysis of viable null alleles revealed that Mecl plays a greater role in response to inhibition of DNA synthesis than Rad53. The loss of survival in mec1 and rad53 null or point mutants in response to transient inhibition of DNA synthesis is not a result of inappropriate anaphase entry but primarily to an inability to complete chromosome replication. We propose that this checkpoint pathway plays an important role in the maintenance of DNA synthetic capabilities when DNA replication is stressed.
\end{abstract}

[Key Words: DN A replication; S-phase; checkpoint pathway; ribonucleotide reductase; nucleotide levels]

Received July 24, 1998; revised version accepted August 11, 1998.

The fidelity of DNA replication is critical to the proper duplication of a cell. $\mathrm{N}$ ot only must cells replicate chromosomes, they must do so with great accuracy; without stretches of unreplicated DNA, without gaps, without replicational slippage in repetitive regions, without recombination causing rearrangements, and without breaks. S phase, the period of the cell cycle during which DNA is replicated, is a period of great vul nerability for a cell. Many complicated processes are undertaken during $S$ phase, including the complete unwinding and replication of enormously complex DNA molecules, and chances for cataclysmic error are high. Interference with DNA replication by DNA damage, nucleotide depletion or imbalance, or polymerase malfunction can lead to a number of del eterious events, including increased mutagenesis, chromosome instability, geneamplification, microsatellite instability, and hyper-recombination (Loeb and Kunkel 1982). Each of these events can have severe consequences for an organism, including cell death, birth defects, and cancer. A number of factors cooperate to ensure the fidelity of DNA replication. These include processivity factors, proofreading functions, mismatch repair proteins, a variety of DNA repair activities, and regulatory pathways that sense DNA damage and replicational stress (Loeb and Kunkel 1982). For example, in response to DNA damage and DNA replicational interference, cells induce the transcription of genes that enhance repair capacities and arrest cell cycle progression to provide time for these repair processes to occur (for review, see Elledge 1996). This ensures that DN A replication and segregation-the critical events that all ow genetic damage to become irreversibly inherited-are delayed until optimal repair can be achieved. In eukaryotes, these regulatory pathways are called checkpoints.

Checkpoint pathways ensure the proper order and timing of cell cycle events, and compromising these pathways contributes to genomic instability and cancer. The outline of the DNA damage response checkpoint pathway in mammals is emerging. ATM (ataxia telangiectasia mutated), a central player, is a member of the lipid kinase family of proteins and is likely a transducer of a DN A damage signal (for review, see El ledge 1996). ATM controls the timely activation of p53, a transcription factor that activates transcription of the cdk inhibitor p21 (Kastan et al. 1992). Cells defective for any of these genes show a defect in $G_{1}$ arrest in response to DNA damage, and ATM mutants are also defective in $G_{2}$ arrest and display radioresistant DNA synthesis. The roles of p53 and ATM in tumorigenesis underscore the importance of the DNA damage response to organismal homeostasis. In the case of ATM, there are additional phenotypes that include specific neural degeneration (Friedberg et al. 1995; Meyn 1995). Recently, an additional mammalian checkpoint gene encoding a protein kinase, Chk1, has been identified (Flaggs et al. 1997; Sanchez et al. 1997). Mammalian Chk1 is phosphorylated in response to DN A damage and is capable of phosphorylating Cdc25C on an inhibitory serine residue (Peng et al. 1997; Sanchez et al. 1997). The fission yeast Chk1 homolog acts downstream of the ATM homol og Rad3 (Walworth et al. 1993; Ford et al. 1994; Carr et al. 1995, Wal worth and Bernards 1996; Furnari et al. 1997). 
In the budding yeast Saccharomyces ceriviseae a number of genes have been identified that control the ability of cells to arrest the cell cycle and/or activate the transcriptional response. Upstream regulators involved in early steps in this pathway include RAD9, RAD17, RAD24, and MEC3, which are required for cell cycle arrest in $G_{1}$ and $G_{2}$ in response to DNA damage. POL2, encoding DN A polymerase 2, DPB11, and RFC5 are upstream components of the cell cycle arrest and transcription pathways that respond to replication blocks (Elledge 1996). Checkpoint signal transducers include MEC 1 and RAD 53, which are required for the S-phase checkpoint as well as the transcriptional and $G_{1}$ and $G_{2}$ arrest responses to DNA damage (Allen et al. 1994; Kato and Ogawa 1994; Weinert et al. 1994). DU N 1, which encodes a protein kinase that is activated in response to DNA damage and replication blocks in a MEC 1- and RAD53dependent manner (Allen et al . 1994), is necessary for the transcriptional response (Zhou and Elledge 1993) and plays a partial role in the $G_{2}$ arrest in response to DNA damage (Pati et al. 1997). MEC1 belongs to the same subfamily of proteins as ATM, underscoring the evolutionary conservation of this pathway (Greenwell et al. 1995; M orrow et al. 1995). MEC1 and TEL1 regulate the phosphorylation of the Rad53p kinase in response to DN A damage and replication bl ocks (Sanchez et al. 1996; Sun et al. 1996).

Whereas MEC 1 and RAD 53 control both the transcriptional and cell cycle responses to DN A damage and replication blocks, it is not clear whether these are the only roles these proteins carry out or whether these proteins play equivalent roles in these responses. In addition, the issue of whether these genes coordinate DN A replication and mitosis in an unperturbed cycle or only in response to replicational stress remains to be resolved. Both genes are essential for viability, perhaps suggesting a role for the checkpoint in each cell cycle, but to date their essential roles have remained obscure. In this study we sought to determine the essential functions of RAD53 and MEC 1 by isolation of dosage suppressors of the null allele of rad53. We have discovered that increasing dNTP synthetic capacity can suppress both rad53 and mecl null al leles. Furthermore, the primary lethal defect in these mutant strains in response to nucleotide depletion is not mitotic entry but a profound defect in the ability to finish chromosomal replication. We propose that one of the roles of this checkpoint pathway is the stabilization of replication structures under conditions of replication inhibition.

\section{Results}

RNR1 overexpression suppresses $\Delta$ rad53 and $\Delta$ mecl lethality

To investigate the essential function of the S-phase checkpoint, we sel ected dosage suppressors of the lethality associated with a deletion of RAD53. A TRP1 $2 \mu$ S. cerevisiae CDNA library under control of the GAL1 promoter (Mulligan and Elledge 1994) was constructed in $\lambda T R P$, converted to plasmid form by cre-lox automatic subcloning (Elledge et al. 1991) and used to transform a rad53 null strain, Y 324, being kept alive by RAD53 on a U RA 3 CEN plasmid, pJA 92 (Allen et al. 1994). Transformants were selected on synthetic complete medium lacking tryptophan (SC - Trp), with gal actose as a carbon source to induce cDNA expression, and replica plated onto the same medium containing 5-fluoro-orotic acid (5-FOA) to select for strains able to grow in the absence of pJA92. We subsequently examined the ability of these 5-FOA ${ }^{r}$ transformants to grow with gl ucose as the carbon source. Because GAL-driven RAD53 is capable of sustaining cell growth under repressed conditions (glucose), choosing only clones that exhibited partial galactose dependence eliminated both the RAD53 background and any plasmid-independent extragenic suppressors. Twelve clones were at least partially dependent on galactose for suppression of $\Delta$ rad53. These plasmids were sequenced and the identities of the encoded genes are listed in Table 1, along with the efficiency with which they suppress the growth defect of rad53 deletion mutants. We called those genes SRL, for suppressors of rad53 lethality. A variety of genes are capable of suppressing $\Delta$ rad53 to varying extents, including a number of transcription factors, both positive and negative. Those suppressors are likely to rescue the lethal ity indirectly, through effects on the transcription of other genes. Two suppressors are putative 26S proteasome components and are al so likel y to be indirect suppressors that act by changing the stability of other proteins that suppress the lethality of the rad53 deletion. Other suppressors consist of a protein kinase (MCK1), a putative chaperone (PDR13), and the regulatory subunit of ribonucleoside diphosphate reductase (RNR1). The remainder, designated SRL1, SRL2, and SRL3, show no similarity to other proteins in the database.

RNR1 overexpression suppresses mecl, indicating a common essential function for RAD53 and MEC 1

Because RAD53 and MEC1 operate in the same checkpoint pathway (Sanchez et al. 1996; Sun et al. 1996), it is possi ble that they are essential for the same reason. In an effort to determine whether these genes have the same essential function, we examined the SRL genes for their ability to suppress $\Delta$ mecl lethal ity. M ost of the suppressors were capable of suppressing the mecl del etion mutant, albeit poorly. Only one plasmid was able to efficiently suppress both the rad53 and mecl deletion mutants (Table 1). This plasmid contained the RNR1 gene encoding a predicted protein product starting with amino acid 22 of Rnrl and continuing to the end of the 888-amino-acid protein. RNR1 was also shown to suppress the lethality of the $\Delta \operatorname{mec} 1 \Delta$ tel 1 and $\Delta \operatorname{mec} 1 \Delta \operatorname{rad} 53$ double mutants (data not shown). RNR1 is an essential gene that encodes the large subunit of ribonucleoside diphosphate reductase (RNR), the rate-limiting enzyme of deoxyribonucleotide synthesis and the target of the DNA synthesis inhibitor hydroxyurea (HU). RNR1 is both inducible by DNA damage and tightly cell cycle 
Table 1. Summary of rad53 and mecl deletion suppressors

\begin{tabular}{|c|c|c|c|c|c|c|}
\hline \multirow[b]{2}{*}{ ORF name } & \multirow[b]{2}{*}{ Gene name } & \multirow[b]{2}{*}{ Function } & \multicolumn{2}{|c|}{$\begin{array}{l}\text { Strength of } \\
\text { suppression }{ }^{\mathrm{a}} \text { of }\end{array}$} & \multirow{2}{*}{$\begin{array}{c}\text { ORF } \\
\text { size (nt) }\end{array}$} & \multirow{2}{*}{$\begin{array}{l}\text { Portion } \\
\text { cloned (nt) }\end{array}$} \\
\hline & & & $\operatorname{rad53}$ & mecl & & \\
\hline YBR112c & SSN6/CYC8/CRT8 & transcriptional repressor & weak & poor & 2898 & $1-600$ \\
\hline YDR173c & ARGR3/ARG82 & transcriptional repressor/activator & good & weak & 1065 & entire \\
\hline YER070w & RNR1/CRT7 & ribonucleoside diphosphate reductase & strong & strong & 2664 & 66-end \\
\hline YHR064c & PDR13 & drug resistance, Hsp70 family & weak & weak & 1716 & 82-end \\
\hline YJL110c & GZF3/NIL2 & transcriptional repressor & weak & poor & 1653 & 637-end \\
\hline YKR091w & SRL3 & & weak & poor & 456 & entire \\
\hline YLR082c & SRL2 & & good & strong & 1176 & entire \\
\hline YN L307c & MCK1 & meiotic protein kinase & poor & poor & 1125 & entire \\
\hline YOR247w & SRL1 & & weak & poor & 630 & entire \\
\hline YOR259c & RPT4/SU G2 & SPB duplication, $26 \mathrm{~S}$ proteasome & good & poor & 1311 & 35-end \\
\hline YOR261c & RPN 8 & $26 \mathrm{~S}$ proteasome & good & poor & 1014 & $76-880$ \\
\hline YPL129w & ANC1/TFG3 & transcription factor & poor & weak & 731 & 161-end \\
\hline
\end{tabular}

aStrength of suppression was judged qual itatively by the ability to grow on 5-FOA after allowing the wild-type RAD 53 U RA 3 or MEC 1 URA3 plasmid to be segregated.

' The extent of each ORF that was contained on each library plasmid was approximated using the sequence of the $5^{\prime}$ end of the insert and the size of the insert, which was approximated by gel electrophoresis. (nt) N ucleotide.

regulated (Elledge and Davis 1990). A gene encoding an alternative large subunit of Rnr, RNR3, is a target gene of the DNA damage and replication interference response pathways and is $80 \%$ identical to RNR1 at the amino acid level. We found that full-length RNR1 and RNR3 are both able to efficiently suppress $\Delta$ rad53 and $\Delta$ mec 1 when expressed from the constitutive GAP promoter on a $2 \mu$ plasmid (pGAP-RNR1, pGAP-RNR3; Fig. 1A).

Low levels of ectopic RN R1 can suppress lethality To examine whether up-regulation of RNR1 or RNR3 was the mechanism through which the other suppressors functioned, N orthern analysis was performed on total RNA isolated from asynchronously growing cultures of each suppressed $\Delta$ rad53 strain. There were no large increases in either RNR1 or RNR3 mRNA levels between wild-type cells and the suppressors (Fig. 1B-D), with the exception of Ssn6. There is a three-fold increase in RNR3 expression when truncated Ssn6 protein is expressed. RNR3 is negatively regulated by SSN6 (Zhou and Elledge 1992); therefore, this truncated Ssn6 might be acting as a dominant-negati ve mutant. The more general failure to detect strong differences in RNR transcription does not completely rule out al tered RNR expression as a mechanism of suppression because very low amounts of exogenously supplied Rnrl are still capable of suppressing $\Delta$ rad53. For example, RNR 1 under GAL1 control can still suppress when grown on glucose (data not shown). Additional support comes from the fact that one additional copy of the RNR1 gene under its own promoter is capable of efficient suppression, indicating that a twofold increase in RNR1 gene dosage is sufficient for suppression.

Mec1 has a greater role than Rad53 in response to genotoxic stress

Mecl and Rad53 are both required for the transcriptional and cell cycle arrest responses to DNA damage and replication blocks. However, it was unclear whether they were equivalent in these functions because only hypomorphic alleles could be compared because of their essential nature. Having common suppressors of mecl and rad53 null mutations al lowed us to examine the phenotypes associated with a complete loss of function. In addition to defects in cell cycle arrest and transcriptional responses, previously isolated point mutants of RAD53 and MEC 1 show a high degree of sensitivity to UV and ionizing radiation, radiomimetic drugs, and $\mathrm{HU}$. $\Delta$ rad53 + pGAP-RNR1 cells show the same degree of sensitivity to $\mathrm{HU}$ and $\mathrm{UV}$ irradiation as rad53-21 point mutants (Fig. 2A,B, circles). In addition, analysis of spindle elongation in $\alpha$-factor-synchronized rad53-21 and $\Delta$ rad53 cells rel eased into media containing $\mathrm{HU}$ indicated that both of these alleles confer equivalent defects in the S-phase checkpoint (Fig. 2C,D, circles). The rad53 null mutant actually exhibits a slower rate of accumulation of anaphaselike spindles, but this parallels the slower rate of budding that is also observed under these conditions (Fig. 2C, circles). Thus, al though RNR1 suppresses the lethality of $\Delta$ rad53, it is unable to suppress the checkpoint and DN A damage sensitivity associated with loss of Rad53 function. This suggests that RNR1 overexpression allows rad53 (and mec1) null cells to tolerate an altered cellular physiology, rather than re storing function to the MEC1 RAD53 pathway.

$\Delta$ mecl + pGAP-RNR 1 cells are also defective in the response to DNA damage and replication blocks but more so than the mec1-21 point mutant, suggesting that mec1-21 is still partially competent in some of its re sponses. When the mec 1 and rad53 null strains are compared, it is clear that the $\Delta$ mecl mutant is significantly more UV- and HU-sensitive (Fig. 2A,B). This indicates that $M E C 1$ has a greater role in response to $D N A$ damage than does RAD53, which is consistent with the fact that Rad53 is downstream of $\mathrm{Mecl}$ in the pathway and indi- 
A

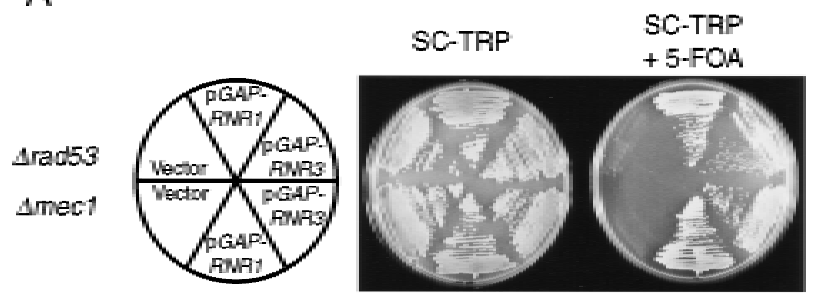

B
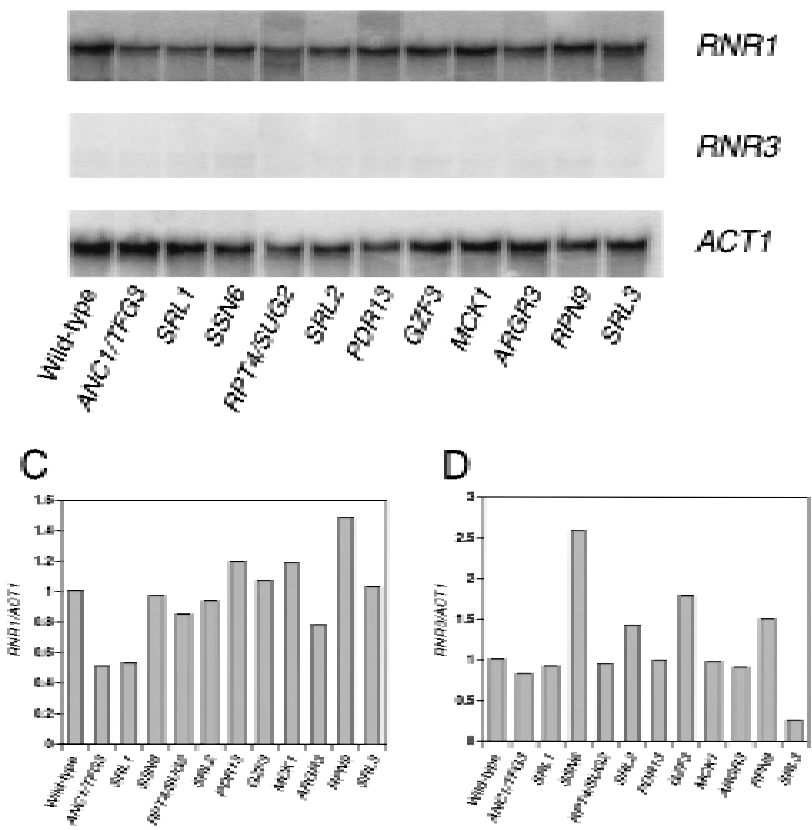

Figure 1. Suppression of null alleles of rad53 and mecl by overproduction of RNR1 and other genes. (A) RNR suppression of $\Delta$ rad53 and $\Delta$ mecl. Y 601, a $\Delta$ rad53 mutant containing a wild-type copy of RAD53 on a URA3 plasmid, and Y602, a $\Delta$ mecl mutant containing a wild-type copy of MEC 1 on a U RA 3 plasmid, were transformed with a TRP plasmid carrying GAPcontrolled RNR1 (pBAD 70) or RNR3 (pBAD 79), or empty vector (pBAD54) as indicated. These transformants were struck onto SC -Trp and SC -Trp +5-FOA to assess the ability of the null alleles to grow in the presence of the RN R expression plasmids. (B) RNR1 and RNR3 levels in suppressed $\Delta$ rad53 strains. Y 81 (wild-type) and Y 324 ( $\Delta$ rad53) strains containing the indicated suppressors were grown to log phase in YPGal at $30^{\circ} \mathrm{C}$. Total RNA was prepared and $\mathrm{N}$ orthern blot analysis was performed using RNR1 (top)-, RNR3 (middle)-, or ACT1 (bottom)-specific probes (see Materials and Methods). (C, D) Phosphorlmager quantitation of the $\mathrm{N}$ orthern blots presented in $\mathrm{B}$. The amount of RNR1 (C) and RNR3 (D) transcript was first normalized to the amount of $\mathrm{ACT} 1$ transcript present in each strain and then to the amount of RNR1 or RNR3 present in wild-type cells.

cates that MEC 1 has functions in addition to its regulation of Rad53. However, inappropriate spindle elongation in the presence of $\mathrm{HU}$ by the mecl null mutant occurs to the same extent as the rad53 null mutant (Fig. 2D). This suggests that the greater degree of lethality experienced by the mecl null mutant in HU may be independent of the defect in preventing anaphase entry.
The possibility that it is an event other than aberrant spindle elongation that commits checkpoint-defective cells to death is addressed further bel ow.

\section{Probing the essential function of Rad53 and Mec1}

To examine the possibility that the lethal defect in $\Delta$ rad53 and $\Delta$ mecl mutants during an otherwise normal cell cycle is low or aberrant RNR1 expression, we measured the accumulation of endogenous RNR 1 mRN A after release from an $\alpha$-factor block in strains deleted for mecl containing additional RNR1 under GAP1 control (TRP1::GAP-RNR1) (see Materials and Methods). To specifically detect endogenous RNR1 mRNA, we used a probe specific for the 3'-untranslated region of the RNR 1 gene that was absent in the TRP1::GAP-RNR1 expression cassette. Endogenous RNR 1 expression in a population of $\Delta$ mec1 TRP1::GAP-RNR1 cells synchronously moving through the cell cycle was compared with that of a MEC1 TRP1::GAP-RNR1 strain. Although the mutant accumulates appreciable amounts of RNR1 transcript, that accumulation is delayed and occurs at a slower rate than that of wild type (Fig. 3B). By the time RNR 1 levels start to decline in $\Delta$ mecl TRP1::GAP-RNR1, there is approximately a 15 to 20 minute difference between it and wild type. A similar phenomenon is observed in $\Delta$ rad53 TRP1::GAP-RNR1 cells (Fig. 3A). To determine whether these differences were due to a defect in RNR1 expression in the mutants or to a general cell cycle perturbation, we examined three other indicators of cell cycle progression. Figure $3 \mathrm{C}$ shows the expression profile of CLN 2 mRN A out of $\alpha$-factor arrest. Like RNR 1, CLN2 expression in the $\Delta$ mecl TRP1::GAP-RNR1 strain is delayed relative to MEC 1 TRP1::GAP-RNR1 cells, with the peak occurring 15 minutes later. The budding profile of the mecl null mutant al so shows a delay (Figs. 3D and $2 \mathrm{C}$ ), indicating a delayed passage through start after $\alpha$-factor arrest. Finally, the FACS profiles (Fig. 3E) clearly show that the mutant cells enter $S$ phase later than, and persist in $\mathrm{S}$ phase longer than, the control cells. These results demonstrate that the MECl pathway plays a complex role in the cell cycle, affecting several aspects of cell cycle regulation. However, whereas the regulation of RNR1 is altered, it appears to be a secondary effect of a general cell cycle perturbation and not a specific target of the MEC1/RAD53 pathway. If the apparent delay and reduced expression of RNR1 was not an artifact of general cell cycle perturbation, then RNR1 levels should also be lower in asynchronous cultures. RNR 1 appears to be expressed at wild-type levels in asynchronous cultures of rad53 and mecl null mutants kept alive with RNR3 (Fig. 3F), supporting the notion that the altered RNR 1 expression in the synchrony experiment is simply a reflection of the slower kinetics of cell cycle progression.

RN R1 overproduction does not enhance the rate of DNA replication

Because low levels of additional RNR1 expression are 
Figure 2. Characterization of checkpoint deficiency of rad53 and mecl null mutants. (A) Viability in $\mathrm{HU}$ of mecl and rad53 null mutants compared to point mutants. Asynchronously growing log phase cultures were treated with $0.2 \mathrm{M}$ $\mathrm{HU}$. Aliquots were removed at timed intervals to determine cell number and to score for viable colony-forming units on YPD plates. The strains used were Y 80 (wild type, ), Y 301 (rad53-21, ๑), Y603 $(\Delta$ rad53 + pGAP-RNR1, O), Y604 (mec1$21, \boldsymbol{\square})$, and $\mathrm{Y} 605$ ( $\Delta \mathrm{mecl}+\mathrm{pGAP}-\mathrm{RNR} 1$, $\square)$. (B) UV sensitivity of mecl and rad53 null mutants compared to point mutants. The same strains as in A were grown asynchronously to log phase at $30^{\circ} \mathrm{C}$ and plated onto YPD. The plates were irradiated at 0 , 20 , or $40 \mathrm{~J} / \mathrm{m}^{2}$, and surviving colony-forming units were cal culated. (C) Budding profiles of checkpoint mutants in HU following release from an $\alpha$-factor block. Logphase yeast cultures were incubated at $30^{\circ} \mathrm{C}$ in YPD supplemented with $10 \mu \mathrm{g} /$ $\mathrm{ml} \alpha$-factor for $3 \mathrm{hr}$. To release from the block, cultures were washed into YPD lacking $\alpha$-factor but containing $0.2 \mathrm{M} \mathrm{HU}$, and al iquots were removed at timed intervals and scored for the presence of a bud. The strains used were $Y 580\left(\mathrm{RAD}^{+} \mathrm{MEC}^{+}\right.$ TRP1::GAP-RNR1, ), Y 301 (rad53-21, ๑), Y606 ( $\Delta$ rad53 TRP1::GAP-RNR1, O), and Y581 ( $\Delta$ mec1 TRP1::GAP-RNR1, $\square)$. (D) Kinetics of spindle elongation of checkpoint mutants in HU following release from $\alpha$-factor. Samples were taken from the same experiment as in $\mathrm{C}$ and stained with anti- $\alpha$-tubulin antibodies. Cells were scored for the presence of an elongated mitotic spindle by indirect immunofluorescence.

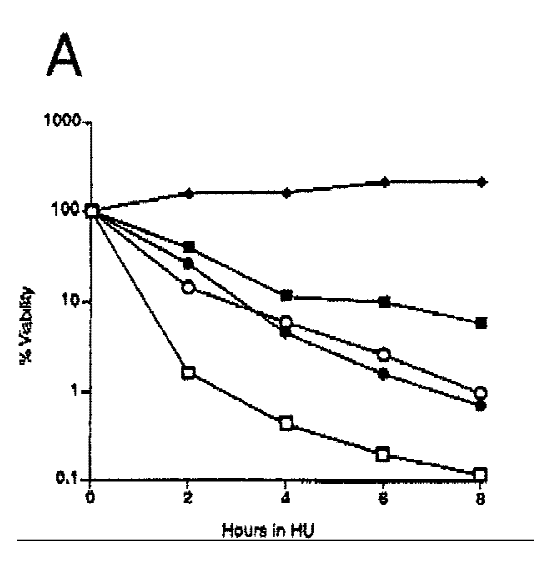

B

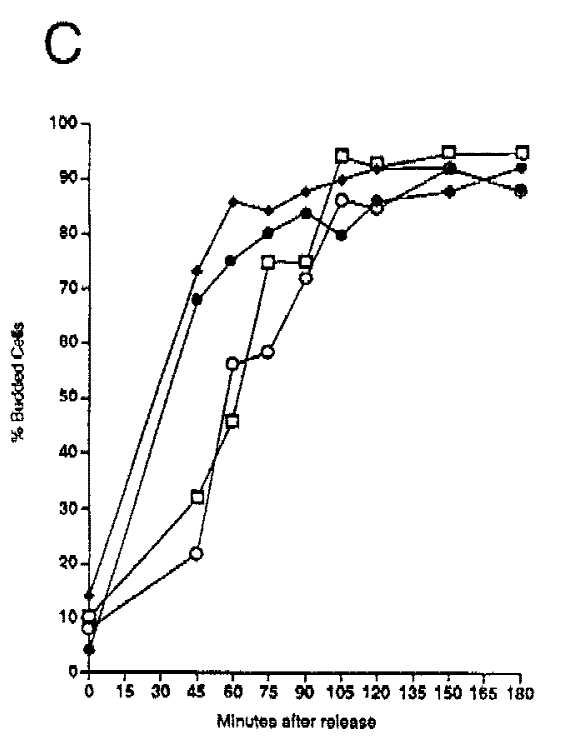

capable of suppressing the lethality of mecl and rad53 mutants, we entertained two general hypotheses for how this suppression might work. The first is based on the assumption that because MEC 1 and RAD53 coordinate S-phase completion and mitosis under certain circumstances, their loss may all ow S phase and mitosis to occur based on their natural timing, akin to a race between $\mathrm{S}$ phase completion and mitotic onset. Thus, by adding additional nucleotides $\mathrm{S}$ phase may be shortened to the point where it is completed prior to a lethal mitosis. The second hypothesis is that the MEC1/RAD53 pathway provides a function other than cell cycle coordination, such that the loss of Rad53 and M ec1 creates a special nucleotide stress or a greater sensitivity to normal nucleotide levels-levels that may be suboptimal for DNA polymerization or fork stability. Because rad53 mutants are sensitive to low nucl eotide levels, we know that nucleotide depletion is toxic. Although the HU sensitivity is generally assumed to be due to inappropriate mitotic entry, this has not been rigorously demonstrated and other explanations exist. For example, nucleotide depletion sensitivity could result from the occasional disassembly of a paused replication complex searching for nucl eotides, and MEC 1/RAD53 mi ght help to restore the function of these (transiently) nucleotide-starved complexes. Providing additional nucleotides in the form of RNR overexpression might prevent this stress from occurring. In both hypotheses, RNR1 overexpression suppresses by providing extra dNTPs; in the first case, the dNTPs would suppress by accelerating the rate of S-phase completion, whereas in the second case they would suppress by preventing a cataclysmic response to perceived nucleotide depletion by reversing that depletion.

To test the first hypothesis, we examined whether S phase was shorter in wild-type cells overproducing RNRI under GAP control. Cells were arrested in $G_{1}$ with $\alpha$-factor, rel eased from the bl ock, and their DNA content was measured by FACS analysis at 2 min intervals. Although a very small effect cannot be ruled out, the overexpression of RNR1 had no apparent effect on the timing of S-phase completion or the overall rate of DNA synthesis (Fig. 4). 
A

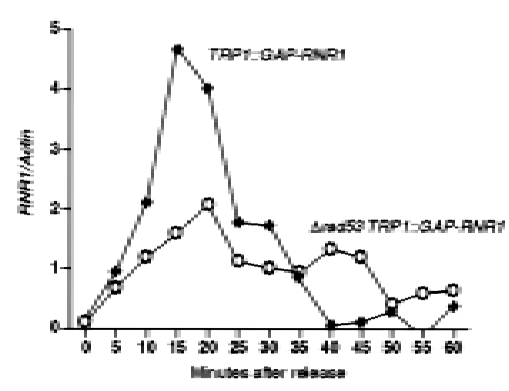

C

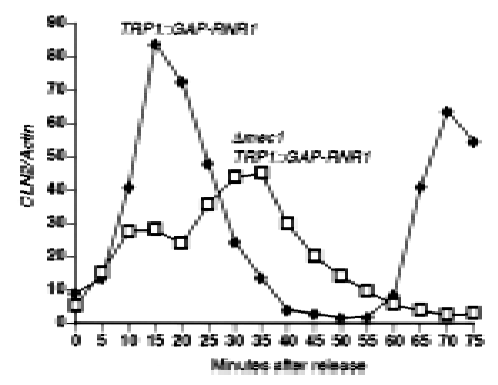

E

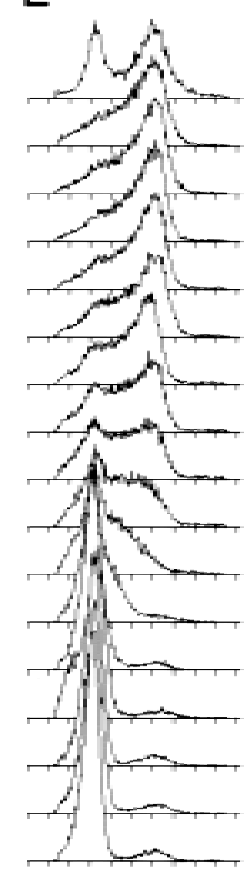

TRP1::GAP-RNA1

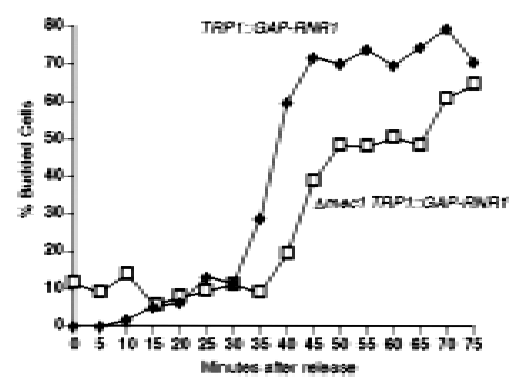

B

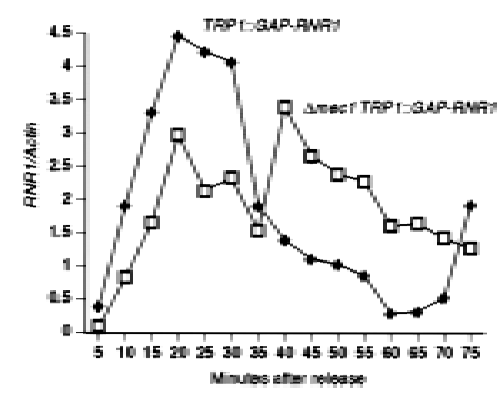

D

$\mathrm{F}$
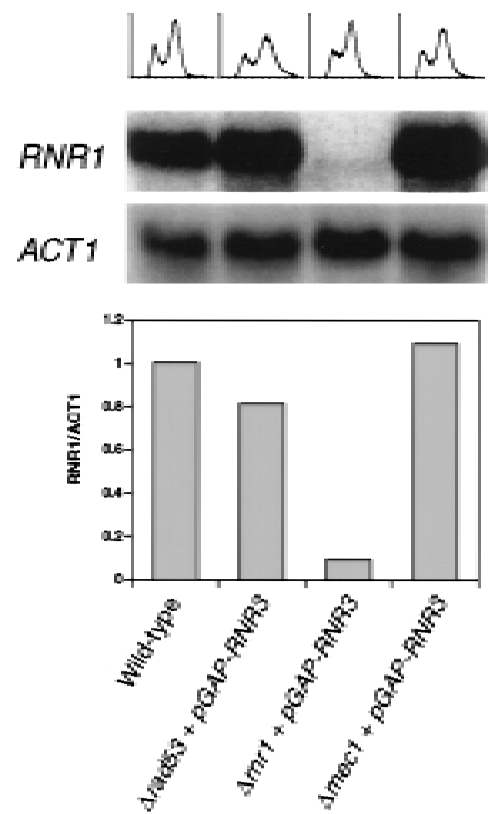

Figure 3. Kinetics of cell cycle events in rad53 and mecl deletion mutants. (A) Accumulation of endogenous RNR1 mRN A in a rad53 del etion mutant. Y607 (RAD ${ }^{+}$TRP1::GAP-RNR1, ) and Y 606 ( $\triangle$ rad53 TRP1::GAP-RNR1, O) were grown at $30^{\circ} \mathrm{C}$ to log phase and arrested with $10 \mu \mathrm{g} / \mathrm{ml} \alpha$-factor for $3 \mathrm{hr}$. Upon release into YPD, aliquots were taken and total RNA was prepared and blotted. The blot was probed with DNA specific to the endogenous RNRI transcript and al so to ACT1 for normalizing to the total amount of RNA in each lane (see Materials and Methods). Quantitation was performed using ImageQuant and the values obtained for each time point were plotted as a function of minutes after $\alpha$ factor release. (B-E) The data presented in parts B-E all come from the same experiment and employed strains $Y 580$ (MEC+ TRP1::GAP-RNR1, ) ) and Y581 ( $\triangle$ mecl TRP1::GAP-RNR1, $\square$ ). (B) Accumulation of endogenous RNR1 mRNA in the mecl null. RN A was harvested, blotted, and probed and quantitated as in A. (C) Accumulation of CLN 2 mRN A in the mecl deletion mutant. The blot used in $B$ was stripped and reprobed with DNA specific to the CLN2 transcript (see Materials and M ethods). (D) Budding profile of the mecl null mutant. A small aliquot of the cells used in B and $C$ was retained for visual analysis of bud growth. The data are represented as the percentage of the total cells that have el aborated a bud at the indicated times. (E) DN A content of $\Delta$ mecl cells as they progress through the cell cycle upon release from an $\alpha$-factor block. A portion of each aliquot used in parts (B-D) was stained with propidium iodide and analyzed by flow cytometry (see M aterials and M ethods). (F) Overall RNR1 mRN A levels in asynchronously growing rad53 and mecl null mutants suppressed by high copy RNR3. Strains were grown to log phase at $30^{\circ} \mathrm{C}$ in YPD. Total RNA was purified from harvested cells, blotted, and probed with DNA specific for RNR1 and ACT1, as noted. Abundance of RNRI transcript was cal culated as noted in A and B and is represented in the bar graph below the autoradiograms. Above each lane in the autoradiograms the FACS profile of each strain is placed at the time the cells were harvested, indicating that there is a simi-

lar cell cycle distribution between them and validating the comparison of mRNA levels. The strains employed were $Y 692$ (TRP ${ }^{+}$ MEC ${ }^{+}$), Y 608 ( $\Delta$ rad53 + pGAP-RNR3), Y 609 ( $($ rnrl + pGAP-RNR3), and Y 610 ( $\Delta$ mec1 + pGAP-RNR3). Y 609 is a deletion of RNR1 that is suppressed by overexpression of RNR3. This provides a control for the specificity of the RNR1 probe used in this experiment.

Delaying mitosis cannot rescue the lethality of mecl and rad53 null mutants

If the outcome of a race between $\mathrm{S}$ phase and mitosis determines lethality, the result could be influenced not only by making $S$ phase happen faster but al so by delaying mitosis. To test this we examined the effects of agents capable of delaying mitosis on mecl and rad53 


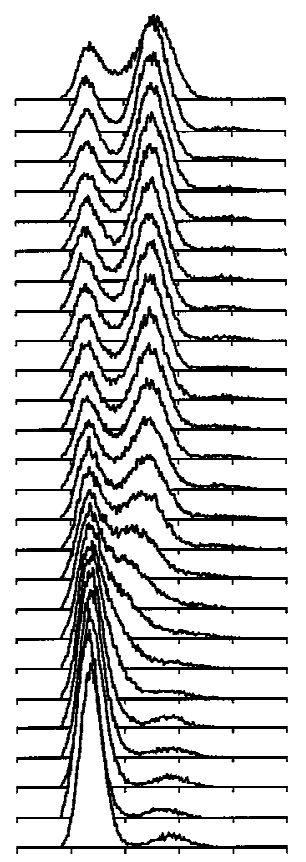

Y300 (trp1-1)

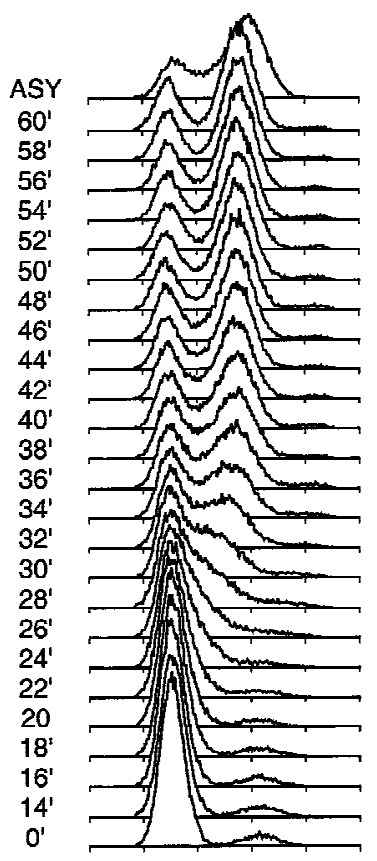

Y580 (TRP1::GAP-RNR1)

Figure 4. RNR1 overproduction does not accelerate progression though $S$ phase. DNA replication timing of $Y 300$ (wild type, trp1-1) and Y580 (TRP1::GAP-RNR1) strains is shown. Cells were grown to log phase at $30^{\circ} \mathrm{C}$ and arrested with 10 $\mu \mathrm{g} / \mathrm{ml} \alpha$-factor for $3 \mathrm{hr}$. U pon release from the $\alpha$-factor block into YPD, samples were taken at close intervals and stained with propidium iodide and analyzed by flow cytometry for the purpose of detecting subtle differences in the rate of replication due to RNR1 overproduction.

mutants. We germinated spores from a $\Delta$ rad53::HIS3/ RAD53 heterozygous diploid on media containing sublethal amounts of benomyl $(15 \mu \mathrm{g} / \mathrm{ml})$, which delays mitosis through activation of the mitotic spindle assembly checkpoint (Elledge 1996). $\mathrm{N} \mathrm{o} \mathrm{His}^{+}$colonies were viable under these conditions. We also streaked rad53 null cells containing RAD53 on a URA3 CEN plasmid (pJA92) onto media containing 5-FOA and $15 \mu \mathrm{g} / \mathrm{ml}$ benomyl but observed no increase in the appearance of $5-\mathrm{FOA}^{r}$ colonies rel ative to the absence of benomyl. mecl and rad53 null mutants are extremely sensitive to low HU levels on plates. We identified the minimal concentration of HU that blocked growth on plates (5 mM) and attempted, unsuccessfully, to suppress the lethality of either mutant with $15 \mu \mathrm{g} / \mathrm{ml}$ benomyl.

Because survival was measured as growth on plates in previous experiments, the concentration of microtubule inhibitors employed was necessarily not sufficient to completely block mitosis, and low levels of suppression might be obscured as a result. To examine this more thoroughly, we tested the ability of a sustained mitotic bl ock to all ow rad53 mutants to recover from a transient HU block (Fig. 5A). rad53-21 mutants were rel eased from a $\mathrm{G}_{1}$ block into media containing $0.25 \mathrm{~m} \mathrm{HU}$. After 30 min, the HU was washed out and the cells were resuspended in media containing $80 \mu \mathrm{g} / \mathrm{ml}$ benomyl with no

$\mathrm{HU}$, and viability was measured over time. Blocking mitosis with benomyl was unable to restore any measure of viability. The inability of benomyl to rescue either the lethality of the null, or the sensitivity of either the null or the point mutant to $\mathrm{HU}$, suggests that the lethal event may be the same in each case (the consequence of nucleotide depletion) and unrelated to whether or not cells are allowed to proceed into mitosis. This is consistent with the fact that in rad53 and mecl null mutants, loss of viability in $\mathrm{HU}$ does not correlate with the degree of spindle elongation (Fig. 2A,D).

rad53 mutants fail to complete DNA replication after a transient replication block

As the cause of lethality in null mutants and HU-treated null and point mutants does not appear to be sol ely due to the relative timing of $\mathrm{S}$ phase and mitosis, it is likely that in rad53 and mecl null cells a lethal event is occur-
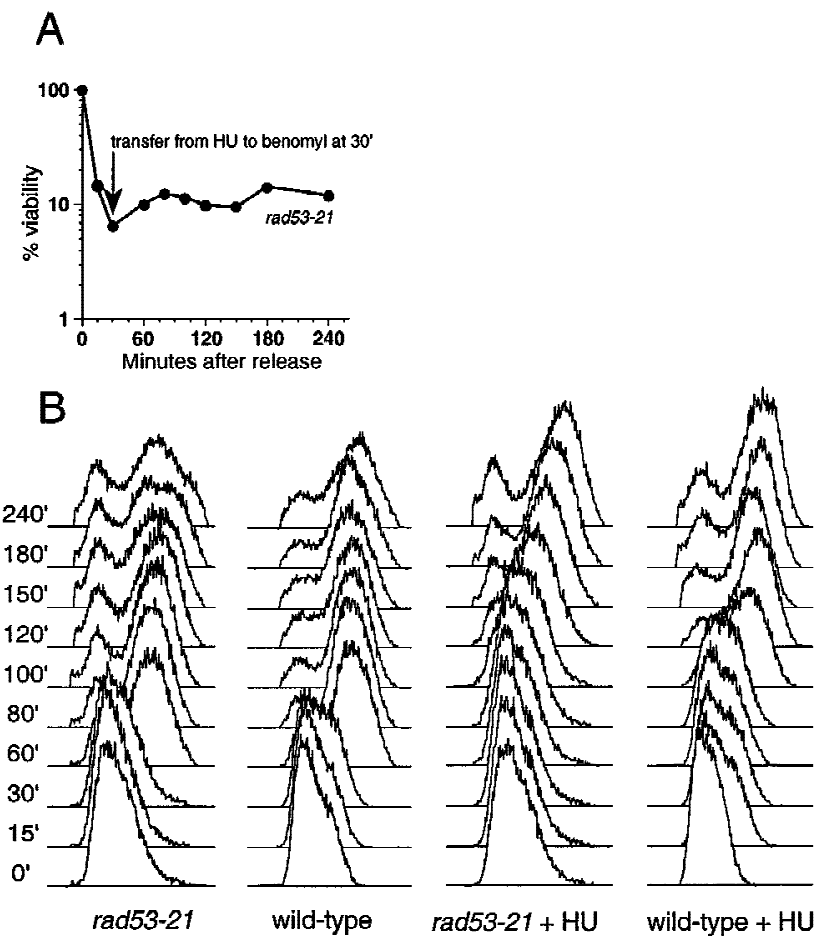

Figure 5. Inability of a microtubule inhibitor to suppress the lethal ity of rad53 mutants transiently exposed to HU. (A) Sensitivity of rad53-21 to $\mathrm{HU}$ in the presence of benomyl. A rad5321 strain, Y 301, was released from $\alpha$-factor arrest into $0.25 \mathrm{~m}$ $\mathrm{HU}$ for $30 \mathrm{~min}$. Following this transient incubation the culture was maintained in $80 \mu \mathrm{g} / \mathrm{ml}$ benomyl, and timed al iquots were plated onto YPD for measurement of viable colony-forming units. (B) FACS analysis of Y 301 (rad53-21) and Y 300 (wild-type) cultures that had been transiently treated with $\mathrm{HU}$. Wild-type and rad53-21 cultures were released from the $G_{1}$ block into either $0.25 \mathrm{M} \mathrm{HU}$ for $30 \mathrm{~min}$ or medium lacking $\mathrm{HU}$, as indicated. At $30 \mathrm{~min}$ after $\alpha$-factor release, cells were washed and transferred into YPD containing $80 \mu \mathrm{g} / \mathrm{ml}$ benomyl. Progress through $\mathrm{S}$ phase was monitored by FACS at the indicated time points. 
ring that commits the cells to death regardless of the timing of the subsequent mitosis. As we described earlier, one such event could be defective DNA replication caused by a condition of nucleotide depletion. To determine whether mutant cells transiently arrested with $\mathrm{HU}$ did in fact have difficulty finishing DNA replication after removal of the replication block, we examined DN A content in rad53-21 and wild-type cells under these conditions. Although the rad53 mutant showed a delay in replicating its DNA relative to wild-type cells transiently treated with $\mathrm{HU}$, it eventual ly accumulated with an approximately $\mathrm{G}_{2}$ DNA content (Fig. 5B), indicating that it recovered the ability to produce sufficient dNTP levels to replicate a genome's worth of DNA.

Because FACS analysis cannot determine to what extent mitochondrial DNA contributes to the amount of $G_{2}$ DNA observed in this experiment, we performed a similar experiment in $\rho^{0}$ rad53-21 mutant strains (Fig. 6A). $\rho^{0}$ rad53-21 mutants were released from $\alpha$-factor into $0.2 \mathrm{~m} \mathrm{HU}$ and $10 \mu \mathrm{g} / \mathrm{ml}$ nocodazole, the $\mathrm{HU}$ was washed away after $1 \mathrm{hr}$, and samples were analyzed for DNA content for up to $3 \mathrm{hr}$ (Fig. 6B, bottom). Under transient $\mathrm{HU}$-treatment conditions that resulted in $75 \%$ lethality (Fig. 6A), we observed the same accumulation of apparent $G_{2}$ DN A content as in the $\rho^{+}$strains (cf. Figs. $6 \mathrm{~B}$ and $5 \mathrm{~B}$ ). The control experiment in the absence of $\mathrm{HU}$ (Figs. 5B and 6B, top) indicates that the effect is specific to $\mathrm{HU}$. The observed delay in replication in rad53-21 mutants was not unexpected because rad53 mutants are unable to induce expression of the RNR1, RNR2, RNR3, and RNR4 genes to quickly increase nucleotide biosynthetic capacity (Allen et al. 1994; Huang and Elledge 1997). Alternatively, the delay could be due to the presence of lesions that occur in the transiently nucleotidestarved cells (e.g., stalled replication complexes or abandoned replication forks) that persist and impede the function of the active replication complexes that subse quently encounter them. These data confirm that rad53-
A
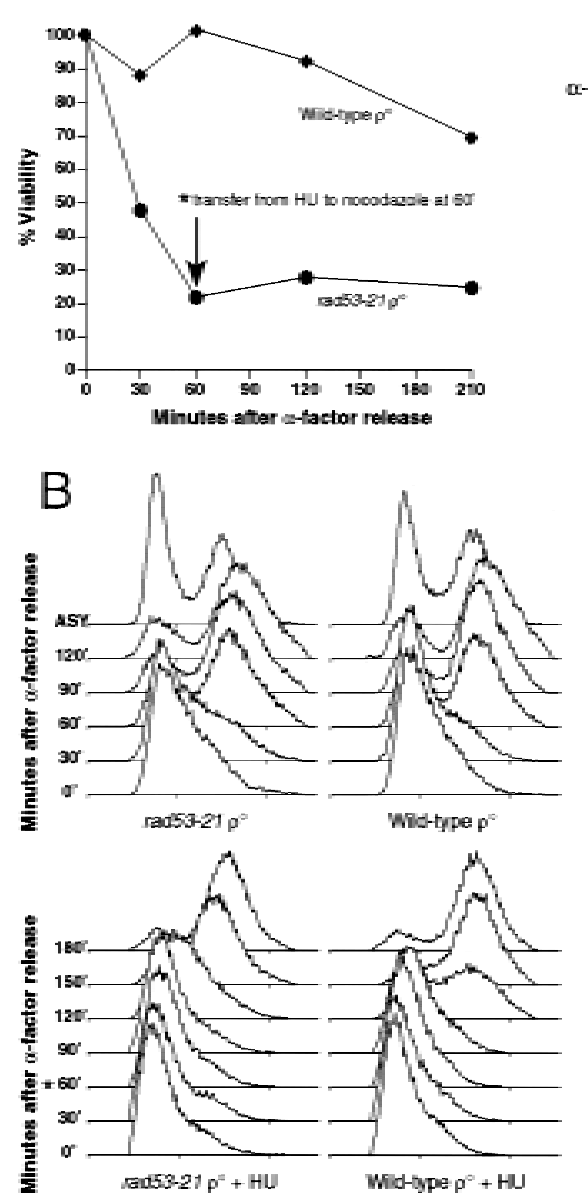

Figure 6. Inability of $\rho^{0}$ rad53-21 mutants to complete chromosomal replication after a transient $\mathrm{HU}$ treatment. Y 623 (wild-type $\left.\rho^{0}\right)$ and Y $624\left(\operatorname{rad53}-21 \rho^{0}\right)$ cells were arrested in $\alpha$-factor for $3 \mathrm{hr}$ and washed into YPD media containing either $10 \mu \mathrm{g} / \mathrm{ml}$ nocodazole or $0.2 \mathrm{~m} \mathrm{HU}$ and nocodazole. After a 60-min incubation, cells were washed and resuspended into YPD medium containing $10 \mu \mathrm{g} / \mathrm{ml}$ nocodazole only and monitored for viability (A), DN A content $(B)$, and chromosome integrity (C,D). (A) Sensitivity of rad53-21 (०) to transient $\mathrm{HU}$ treatment in the presence of nocodazole. Wild-type ( $)$ is shown for comparison. (B) Flow cytometric analysis of the DNA content of wild-type and rad53-21 strains. Transiently HU-treated cultures are shown at bottom, with the asterisk $(*)$ indicating the time at which the cells were washed out of HU. (Top) Cultures released from $\alpha$-factor into nocodazole only. (C) CHEF gel of chromosomes from wild-type (left) and rad53-21 (right) strains transiently treated with HU. The vertical bar over each lane indicates time points at which HU was present (shaded bars) or had been washed out (open bars). The two chromosomes that were used in part (D) are indicated. (D) Quantitation of replication of chromosomes from wild-type $\left[\rho^{0} \mathrm{Chr} A\right.$ $(\diamond)$ and $\left.\rho^{0} \mathrm{Chr} B(\diamond)\right]$ and rad53-21 [rad53$21 \rho^{0} \mathrm{Chr} A(\bullet)$ and rad53-21 $\rho^{0} \mathrm{Chr} \mathrm{B}(\bigcirc)$ ] cultures that had been transiently treated with $\mathrm{HU}$ and resolved by $\mathrm{CHEF}$ in $\mathrm{C}$. The two chromosomes examined are indicated in C. The amount of fully duplicated chromosomes in the rad53 mutants precisely correl ates with the percentage survival. Intensities of the bands were quantitated using N IH Image software and plotted as a function of time after rel ease from $\alpha$-factor and plotted in arbitrary units. 
21 cells are delayed but not deficient in restoring DNA synthetic capability after transient HU treatment. However, the cells are clearly dying, and forestalling mitosis with microtubule destabilizing drugs has no effect on this.

FACS anal ysis measures only bulk DNA content, and it cannot determine whether a small percentage of the DNA is unreplicated or, in the case of the previous experiment, whether the apparently replicated chromosomes at the end of the experiment are intact. To examine the integrity of chromosome structure, we employed pulsed-field gel el ectrophoretic (PFGE) analysis. Incompletely replicated chromosomes fail to enter a pulsedfiel d gel because of the presence of forks and replication bubbles that impede migration (Hennessy et al. 1991). Chromosomal DNA was prepared from the cultures of wild-type $\rho^{0}$ and rad53-21 $\rho^{0}$ mutant cells that had been treated transiently with $\mathrm{HU}$ and kept in the presence of nocodazole. At timed intervals, DNA from these cells was prepared and examined by PFGE (Fig. 6C) and quantitated densitometrically (Fig. 6D) (see Materials and M ethods). Transient HU treatment delayed the re-entry of chromosomes from wild-type cells, consistent with the kinetics observed by FACS analysis. In contrast, chromosomes from the rad53 mutant never reentered the gel, even during a 6-hr mitotic block. Similar results were obtained with mecl mutants (data not shown). Quantitation of the intensities of two chromosome bands, designated $A$ and $B$, shows that wild-type chromosomes double in intensity from $150 \mathrm{~min}$, indicating completed replication. rad53 chromosomes reappear at $180 \mathrm{~min}$ at half the original intensity, indicating that a quarter of the population has properly completed DNA synthesis, consistent with the survival data. This indicates that in addition to experiencing a significant delay in the recovery of bulk DNA synthetic capacity, when the rad53 mutant's chromosomes do eventual ly become apparently fully replicated (by FACS analysis), they have a profoundly abnormal structure (by PFGE).

Genetic interactions between the checkpoint and origin initiation machinery

We have described defective DNA replication as a consequence of transient nucleoti de depl etion in checkpoint mutants. Because checkpoint null mutants can be suppressed by increasing nucleotide biosynthetic capacity, it is likely that the null mutants experience a nucleotide depletion and die for the same reason as hypomorphic mutants that experience a transient nucleotide depletion. Therefore, an important issue is the nature of the perceived nucleotide depletion in checkpoint null cells. These mutants could be sensitive to the normal dNTP levels present in each cell cycle, or alternatively, the absence of the checkpoint could create a nucleotide depletion to which the cells cannot subsequently respond. In the latter case, the mechanism could be a direct failure to up-regulate RNR activity or an indirect consequence of a failure to properly regulate the nucleotide consumption of other cellular machinery. While in- vestigating the genetic interactions between checkpoint mutants and origin-firing mutants, we have uncovered support for the idea that timing of origin firing may contribute to the nucleotide depl etion that kills checkpoint null mutants. The temperature-sensitive origin firing mutant orc2-1 (Liang et al. 1995) displays an extended duration of $S$ phase upon rel ease from an $\alpha$-factor arrest, even at the permissi ve temperature (data not shown). To determine whether this might be mimicking the effect that HU has on S phase, we constructed orc2-1 mec1-21 and orc2-1 rad53-21 double mutants. Surprisingly, both double mutants are viable, suggesting that the lengthened S phase in orc2-1 is a qualitatively different phenomenon than that caused by HU treatment, which kills these checkpoint mutants. Even more startling is the fact that the mec1-21 mutation, but not the rad53-21 mutation, can suppress the temperature sensitivity of orc2-1 (Fig. 7A) at $30^{\circ} \mathrm{C}$. This observation suggests that the checkpoint pathway is acting antagonistically to the origin-firing defect of orc2-1.

The suppression of orc 2 by a mec 1 mutation bears on the essential function of the DNA replication checkpoint because if there is an antagonistic interplay between checkpoint genes and origin-firing genes at the level of origin firing, then it could be that inappropriate origin firing in checkpoint null mutants creates a nucleotide depletion that commits the cel Is to lethality. If true, then origin firing mutants might be expected to abrogate this effect and suppress the lethality of check-

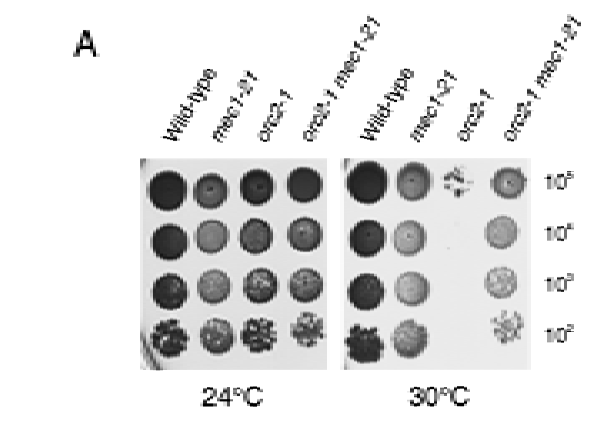

B

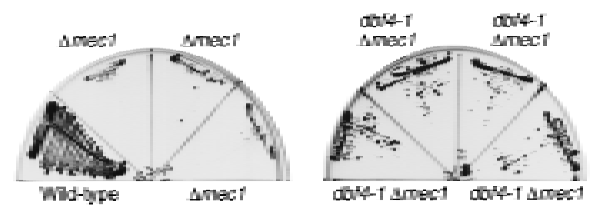

Figure 7. Genetic interactions between mecl mutants and origin-firing mutants. (A) Suppression of orc2-1 by the mec1-21 mutation. Y 300 (wild-type), Y 604 (mec1-21), Y 611 (orc2-1), and Y 612 (orc2-1 mec1-21) cultures were grown to log phase in YPD at $24^{\circ} \mathrm{C}$. Serial dilutions of $10^{5}, 10^{4}, 10^{3}$, and $10^{2}$ cells were spotted onto YPD plates at either $24^{\circ} \mathrm{C}$ (left) or $30^{\circ} \mathrm{C}$ (right). (B) Suppression of $\Delta \mathrm{mec} 1$ by dbf4-1. Representative $\Delta \mathrm{mecl} \mathrm{dbf} 4-1$ double mutants (Y613-Y616) containing MEC1 on a URA3 CEN plasmid (pBAD45) were struck to 5-FOA plates to identify suppressors of the mecl null mutation. The wild-type and $\Delta$ mecl controls that were used in this experiment were isolated from the same cross as the double mutants. 
point null mutants. The concept that the checkpoint and the origin-firing machinery specifically interact with each other is further supported by recent work (Santocanale and Diffley 1998, and pers. comm.) indicating that the timing of origin firing is negatively regulated by the DNA replication checkpoint pathway. To further explore this idea we examined interactions between the checkpoint pathway and the Dbf4/C dc7 complex, a protein kinase that is required for origin initiation (Jackson et al. 1993). We tested dbf4-1 and cdc7-1 mutants for suppression of $\Delta$ rad53 and $\Delta$ mecl by isolating double mutants that contained the wild-type alleles of RAD53 or MEC 1 on a URA 3 plasmid. These strains were struck onto plates containing 5-FOA to assess their ability to grow in the absence of checkpoint gene product. We found that $\Delta$ mecl but not $\Delta$ rad53 was suppressible by dbf4-1 and cdc7-1 (Fig. 7B, data not shown), supporting the plausibility of this idea. Why mecl and not rad53 mutants would exhibit these interactions with origin firing mutants is not clear, but the explanation may lie in the additional functions of $\mathrm{Mecl}$ somehow impinging on these events or in a more complex relationship between origin firing and checkpoint function, as detailed in the Discussion.

\section{Discussion}

Cell cycle checkpoints have been thought of primarily as surveillance mechanisms that respond to aberrations in cellular structures, such as DN A damage or replication blocks, and prevent catastrophic cell cycle transitions. Unlike the checkpoint genes specific for DN A damage, those involved in the DNA replication checkpoint are essential for viability. The fact that all known replication interference checkpoint genes in S. cerevisiae are essential is an indication either that events occurring during the course of a normal cell cycle require the coordinating activities of this checkpoint or that the DNA replication checkpoint genes have activities in addition to the cell cycle coordination traditionally thought to be their primary function (Weinert and Hartwell 1988). We investigated this poorly understood aspect of checkpoint function by performing a high copy suppressor screen of the lethal rad53 null mutation. We found that overproduction of RNR1 eliminated the requirement for both MEC1 and RAD53, indicating an interaction between nucleotide levels and checkpoint function even in the absence of nucleotide-depleting drugs. We also determined that lethality caused by nucleotide stress in checkpoint-deficient cells can be attributed to failure of replication structures to completely recover from the immediate effects of nucleotide depletion, suggesting that replicational stress due to suboptimal nucleotide levels may occur during a normal cell cycle.

\section{Functional distinction between MEC 1 and RAD53}

The mecl and rad53 alleles that were previously available for study were necessarily hypomorphic and not complete loss-of-function alleles. This has made deter- mination of the relative roles played by each in the checkpoint pathway impossible to definitively establish. The existence of a common suppressor al lows a direct comparison of the two null mutants with existing hypomorphic alleles and with each other. The UV and HU sensitivities of the mec1-21 mutant are much less severe than the mecl null mutant, indicating that the mecl-21 allele retains significant residual function. The UV and $\mathrm{HU}$ sensitivities of the rad53-21 and rad53 null mutants are very similar. Furthermore, the kinetics and extent of spindle elongation in $\mathrm{HU}$-treated rad53-21 mutants are essentially indistinguishable from that of both rad53 and mecl null mutants after general cell cycle perturbations are taken into account, indicating that rad53-21 can be considered to be nearly completely defective for the cell cycle delay function.

The major point of similarity between the mecl and rad53 null strains is the fact that even moderate RNR1 overproduction can efficiently suppress them both. Furthermore, a rad53 mecl doubl e null mutant is al so easily suppressible by RNR1 (data not shown). This indicates that the essential functions of both genes are the same. Moreover, using the common suppressor approach we can state unequivocally that there is a functional distinction between RAD53 and MEC 1 observable at the level of sensitivity to UV irradiation and HU treatment, with MEC1 contributing more to resistance than RAD53. Given that the kinetics of anaphase entry of rad53 and mecl null mutants in the presence of $\mathrm{HU}$ are very similar to each other, we believe that the actual cell cycle regulatory functions of the two gene products are there fore also similar but that MEC1 has additional roles required for recovery from replicational stress. This is al so consistent with the fact that MEC 1 acts upstream of RAD53 in the checkpoint pathway and is required for its phosphorylation in response to DN A damage and replication blocks.

What is the essential function of the S-phase checkpoint?

Whereas RAD53 and MEC 1 are essential genes in S. cerevisiae, their homologs in Schizosaccharomyces pombe, $\mathrm{cds1}^{+}$and $\mathrm{rad}_{3}{ }^{+}$, respectively, are not (Al-Khodairy et al. 1994; Murakami and Okayama 1995). The MEC 1-related gene ATM is also dispensable for cell growth in humans and mice (Barlow et al. 1996; Elson et al. 1996; Xu et al. 1996). This suggests that the essential natures of MEC 1 and RAD53 are reflections of a checkpoint requirement that manifests in every cell cycle in S. cerevisiae. Our findings that RNR 1 and RNR3, the rate-limiting regulatory subunits of ribonucleotide reductase, are dosage suppressors of the lethality of the mecl and rad53 null mutations support this idea and indicate that the essential function of these genes involves maintaining an adequate nucleotide supply, as opposed to responding to some kind of DNA damage. The fact that low amounts of exogenously supplied RNR1 can efficiently suppress lethal ity suggests that the defect responsible for lethality is just below the threshold for survival. However, RNR 1 
can do little to overcome the effects of exposure to the RNR inhibitor $\mathrm{HU}$, which requires full activation of the checkpoint for a prolonged period of time.

dNTPs levels are highly regulated (for review, see Elledge et al. 1992). The mRN A for RNR1 is tightly cell cycle regulated, the mRN As for all four RNR genes are inducible in response to DNA damage and replication blocks, the substrate specificity of the reductase is modulated by particular dNTPs to ensure an equal supply of all four dNTPs, and dATP feedback inhibits the overall activity of the enzyme to prevent excessive build up of dNTPs. An important question is why the levels of dN TPs in mecl and rad53 mutants are insufficient for survival. One possi bility is that mecl and rad53 cells are simply more sensitive to normal levels of nucleotides. Perhaps nucleotide levels are normally maintained at a level that is limiting for polymerase function. In vitro it has been shown that high nucleotide levels lead to increased misincorporation rates because proofreading mechanisms have less time to function before the next nucleotide is inserted (Fersht 1979). Thus, it is possible that normal in vivo nucleotide levels cause polymerase pausing in a state that is deleterious in the absence of the replication stress response pathway. A second possibility is that the checkpoint has a direct role in up-regulating dNTP synthesis during $S$ phase such that the loss of checkpoint function would actually cause a nucleotide depletion to which it then would not be able to respond. RAD53 does regulate the transcription of RNR1, RNR2, RNR3, and RNR4 in response to $H U$ treatment and DN A damage; however, the viable rad53-21 allele is completely defective for this transcriptional regulation (Allen et al. 1994; Huang and Elledge 1997), suggesting that this function is not specifically lacking in null mutants. If up-regulation of nucleotide synthesis is regulated by the checkpoint, the defect is not at the level of RNR1 accumulation because RNR1 levels appear to be normal in the null mutants. Furthermore, overproduction of RNR2 and RNR4 fail to suppress rad53 lethality (data not shown). A third possibility is that in the absence of the checkpoint, a secondary event causes a more rapid consumption of dNTPs such that their levels are lower than normal, mimicking HU treatment. This, together with an inability to respond to such a nucleotide depletion, however transient, could cause lethality.

Currently we cannot distinguish between the three models presented in the preceding paragraph. However, the third model, indirect nucleotide depletion as a secondary effect of checkpoint deficiency, has recently gained support. The firing of late replication origins is advanced in rad53 and mecl mutants (Santocanale and Diffley 1998, and pers. comm.). Consistent with this observation, we found that the mec1-21 point mutant suppresses the temperature sensitivity of mutations in ORC2, a gene required for origin recognition and firing. N ormally at the $\mathrm{G}_{1}-\mathrm{S}$ transition, up-regulation of ribonucleotide reductase and the triggering of replication origins occur by separate but parallel regulatory networks. Yet the activation of replication complexes and the dN TP supply must be coordinated because firing of ori- gins with insufficient nucleotide levels would cause a condition of effective nucleotide deprivation. The Sphase checkpoint pathway may provide this coordination. Failure to do so would result in premature or excessive origin firing as observed in mecl and rad53 mutants. The presence of more origins replicating DNA at the same time might consume nucleotides faster than they can be synthesized, leading to DNA replicative stress, a checkpoint requiring situation. RNR1 overexpression could alleviate this problem without restoring checkpoint function. We tested this by artificially slowing down origin firing in checkpoint mutant backgrounds using temperature-sensitive dbf4-1, cdc7-1, and orc2-1 mutants. Although these mutants were unable to suppress the lethality of rad53 null mutants, we have found that mutations in dbf4 and cdc7 can suppress the mecl null mutant. The inability to suppress the rad53 null mutation might indicate a novel role for RAD53 relative to $M E C 1$, or a possible redundancy in RAD53 regulation. We have shown previously that TEL1, a MEC1 homolog, can activate Rad53 to a limted degree (Sanchez et al. 1996). Thus, it is possible that a rad53 null mutant could have a more severe defect than a mecl null mutant under certain circumstances. In addition, it is possible that dbf4 mutants can suppress the lethality of rad53 null mutations but that the double mutant then dies because of a condition unique to the rad53 null mutation. In support of such a possibility we have observed that dbf4-1 rad53-21 and cdc7-1 rad53-21 double mutants are inviable (B.A. Desany and S.J. Elledge, unpubl.).

The genetic interactions between the checkpoint and origin initiation pathways support the notion that the MEC 1/RAD53 pathway is acting antagonistically to the origin firing machinery for the purpose of maintaining coordination between the initiation of DNA replication and the nucl eotide supply. Furthermore, we believe that the simplest interpretation of our data is that in the absence of the checkpoint pathway, nucleotide levels become limiting either by increased consumption due to increased origin-firing or by an unknown mechanism, and this situation, together with the absence of the ability to properly respond to nucl eotide depl etion, results in lethality.

What is responsible for lethality in the presence of $\mathrm{HU}$ ?

Replication checkpoint-defective cells die rapidly when exposed to $\mathrm{HU}$, and inappropriate spindl e el ongation has been thought to be responsible for this lethal ity. However, microtubule-inhibiting drugs are incapable of rescuing either the lethality of the mecl and rad53 null mutants or the HU sensitivity of the point mutants. Additionally, the spindle elongation defects of the mecl and rad53 null mutants are similar to each other, whereas their sensitivities to $\mathrm{HU}$ are significantly different. We interpret this to indicate that spindle el ongation, rather than being the sole lethal event in these cells, is being misregulated independently of another event that is irreversibly committing cells to death. This is similar 
to the results obtained in S. pombe with mutations in cds1, the gene rel ated most closely to RAD53. cds1 mutants die in response to $\mathrm{HU}$ treatment but do not appear to enter mitosis prematurely (M urakami and Okayama 1995; Lindsay et al. 1998). Similar results were obtained with husl mutants (Enoch et al. 1992). Although there was no attempt to artificially delay mitotic entry to rescue the lethality in those experiments, it is likely that these mutants are dying for the same reasons as rad53 mutants in HU. Our experiments show that rad53 mutant cells have a reduced ability to synthesize intact chromosomes following transient nucleotide depletion. This is not due to an inability to resume dN TP production because bulk DNA synthesis resumes after the block is removed, al beit with slower kinetics than wild type. Whether the structures that prevent chromosome migration in pulsed field gels are normal replicational intermediates that persist much longer than usual, such as replication forks, or are structurally aberrant in some way because of errors resulting from stalled polymerases is not clear. Stalled replication complexes could occasionally disintegrate and require checkpoint-mediated restoration. Alternatively, the collapse of complexes on converging forks could leave lethal gaps of unreplicated DN A. A berrant DN A repair could al so lead to defective chromosomal structure. Although it is not known whether the MEC 1/RAD53 pathway directly controls repair processes, it is clear that HU causes damage because rad51 and rad52 mutants are very sensitive to HU (Allen et al. 1994).

Taken together, our results suggest that inviability of rad53 and mecl null mutations is not due to premature mitotic entry but to an inability to survive with the existing nucleotide levels present in those mutants. Furthermore, our results indicate that the lethal ity resulting from limiting nucleotides is not purely a cell cycle transition phenomenon but is due instead to the profound inability of these mutants to properly carry out chromosomal replication after transient nucleotide depletion. Although this defect could be caused by misregulation of an as yet unappreciated aspect of cell cycle coordination distinct from anaphase commitment, it is clearly not the onset of anaphase that is causing lethality in these mutants because preventing anaphase cannot restore viability after a transient replication block. We favor the model that the checkpoint pathway is more than a cell cycle response. The fact that mecl and rad53 null mutants appear to be equally checkpoint defective but have significantly different sensitivities to DNA-damage and replication-blocking agents suggests that this pathway controls repair activities in addition to coordination of cell cycle transitions. In this light, these pathways should be considered to be DNA-damage and DNA replication-block stress-response pathways as opposed to sol ely concerning themsel ves with cell cycle transitions.

\section{Materials and methods}

Yeast growth conditions

Y east cells were grown at $30^{\circ} \mathrm{C}$ unless indicated otherwise. Rich and SC medium was formulated according to Kaiser et al. (1994). The carbon source was glucose, unless indicated, in which case the glucose was replaced by galactose. Where indicated, 5 -FOA was used at $0.1 \%$, and benomyl in solid media was used at $15 \mu \mathrm{g} / \mathrm{ml}$.

Isolation of SRL genes

Strain Y 324 (see text and Table 2) was grown in YPD and transformed with a $2 \mu$ TRP1 S. cerevisiae CDN A library (ATTC nos. 87288 and 47059 ) using the lithium acetate method. Transformants were plated on SC - Trp GAL (containing gal actose) and replica-plated to SC -Trp GAL supplemented with 5-FOA. Positive clones were tested for their ability to grow on SC -Trp supplemented with $100 \mathrm{~mm} \mathrm{HU}$. N egatives were then struck to either YPD or YPD with the glucose replaced by gal actose (YPGal). Clones that displayed any degree of galactose-dependent growth were tested for repeatability by plasmid rescue and retransformation of Y324, followed by verification of 5-FOA resistance. These final positive clones were christened SRL genes.

\section{RNA purification and Northern blotting}

RNA purification and Northern blotting were performed as described ( $\mathrm{N}$ avas et al. 1995). For detection of the endogenous RNR1 transcript in the presence of exogenously provided RNR1, we used a HindlII-Spel fragment as a probe corresponding to nucleotides 2642-3317 of the 3' end of the RNR1 transcript. These sequences are not present on the exogenous RNRI expression constructs. For detection of CLN 2 mRN A, we probed using a Styl fragment of CLN2 comprising nucleotides 4601541 of the 1638 nucleotide ORF.

Quantitation of bands was performed by exposing the blots to a Storage Phosphor Screen (M olecular Dynamics, Sunnyvale, CA) and using ImageQ uant software to quantitate the band intensities. In all cases, the lane background was subtracted from each band prior to normalization to the loading control (ACT1).

\section{HU - and U V-killing assays}

For HU killing, cultures were grown to log phase in YPD, whereupon the medium was replaced with YPD +0.2 M HU (unless indicated otherwise), and aliquots were removed and plated on Y PD at timed intervals and al lowed to grow for several days at $30^{\circ} \mathrm{C}$. For UV killing, cells were grown to log phase in YPD, plated on YPD, and irradiated (Stratagene UV Stratal inker 1800 ) with 0,20 , or $40 \mathrm{~J} / \mathrm{m}^{2}$ prior to incubation at $30^{\circ} \mathrm{C}$.

\section{Synchronization of cells in $G_{1}$ phase}

Strains were grown to log phase in YPD (pH 3.9), treated with 10 $\mu \mathrm{g} / \mathrm{ml} \alpha$-factor for $1.5 \mathrm{hr}$, and supplemented with an additional $5 \mu \mathrm{g} / \mathrm{ml} \alpha$-factor for another $1.5 \mathrm{hr}$. Cells were then centrifuged and resuspended in YPD containing the $0.2 \mathrm{M} \mathrm{HU}, 0.25 \mathrm{~m} \mathrm{HU}$, $80 \mu \mathrm{g} / \mathrm{ml}$ benomyl, and/or $10 \mu \mathrm{g} / \mathrm{ml}$ nocodazole as indicated in the individual experiments.

\section{Staining of cells for microtubule visualization}

Cells were fixed by the addition of $5 \%$ formal dehyde to growing cultures and all owed to stand for at least $4 \mathrm{hr}$ at $4^{\circ} \mathrm{C}$. Cells were washed in PBS, and microtubules were immunostained using the antitubulin antibody YOL1/34 and a FITC-conjugated secondary antibody as described (Allen et al. 1994). 
Desany et al.

Table 2. Strains and plasmids used in this study

\begin{tabular}{|c|c|c|}
\hline Strain & Genotype & Source \\
\hline Y81 & MAT $\alpha$ trp1-1 ura3-1 his3-11,15 leu2-3,112 ade2-1 can1-100 & Allen et al. (1994) \\
\hline Y 300 & MATa trp1-1 ura3-1 his3-11,15 leu2-3,112 ade2-1 can1-100 & Allen et al. (1994) \\
\hline Y 301 & as Y 300 rad53-21 & Allen et al. (1994) \\
\hline Y 312 & as Y323 $\Delta$ rad53::HIS3/RAD53 & Allen et al. (1994) \\
\hline Y 323 & $\begin{array}{l}\text { MATa/ } \alpha \text { trp1-1/trp1-1 ura3-1/ura3-1 his3-11,15/his3-11,15 } \\
\text { leu2-3,112/leu2-3,112 ade2-1/ade2-1 can 1-100/can 1-100 }\end{array}$ & Allen et al. (1994) \\
\hline Y 324 & as Y81 $\Delta$ rad53::HIS3 + pJA92 & Allen et al. (1994) \\
\hline Y580 & as Y 300 TRP1::GAP-RNR1 & this study \\
\hline Y581 & as Y $300 \Delta$ mec1::HIS3 TRP1::GAP-RNR1 & this study \\
\hline Y 601 & as Y $300 \Delta$ rad53::HIS3 +pJA92 & this study \\
\hline Y 602 & as Y300 $\Delta$ mec1::HIS3 + pBAD45 & this study \\
\hline Y 603 & as Y300 $\Delta$ rad53::HIS3 + pBAD 70 & this study \\
\hline Y 604 & as Y 300 mec1-21 & this study \\
\hline Y 605 & as Y300 $\Delta$ mec1::HIS3 + pBAD 70 & this study \\
\hline Y 606 & as Y300 $\Delta$ rad53::HIS3 TRP1::GAP-RNR1 & this study \\
\hline Y 607 & as Y 300 TRP1::GAP-RNR1 & this study \\
\hline Y 608 & as Y $300 \Delta$ rad53::HIS3 + pBAD79 & this study \\
\hline Y 609 & as Y300 $\Delta$ rnr::HIS3 +pBAD 79 & this study \\
\hline Y 610 & as Y $300 \Delta$ mec1::HIS3 + pBAD 79 & this study \\
\hline Y 611 & as Y 300 orc2-1 & this study \\
\hline Y 612 & as $\mathrm{Y} 300$ orc2-1 mec1-21 & this study \\
\hline Y 613-616 & as Y 300 dbf4-1 $\Delta$ mec1::HIS3 + pBAD45 & this study \\
\hline Y 617 & as Y $323 \Delta$ mec1::HIS3/MEC1 & this study \\
\hline Y 618 & as Y323 $\Delta$ rad53::HIS3/RAD53 TRP1::GAP-RNR1/trp1-1 & this study \\
\hline Y 619 & as Y323 $\Delta$ mec1::HIS3/MEC1 TRP1::GAP-RNR1/trp1-1 & this study \\
\hline Y 620 & as $\mathrm{Y} 81 \mathrm{mec} 1-21$ & this study \\
\hline Y 621 & as Y323 orc2-1/ORC2 mec1-21/MEC1 & this study \\
\hline Y 622 & as Y323 dbf4-1/DBF4 $\Delta$ mec1::HIS3/MEC1 & this study \\
\hline Y 623 & as Y $300 \rho^{0} \mathrm{HIS} 3$ & this study \\
\hline Y 624 & as Y $301 \rho^{0} \mathrm{HIS3}$ & this study \\
\hline Y 692 & as $\mathrm{Y} 300 \mathrm{TRP}^{+}$ & this study \\
\hline YCH266 & as Y $81 \mathrm{dbf4-1}$ & $\begin{array}{l}\text { C. Hardy (Washington } \\
\text { University, St. Louis, MO) }\end{array}$ \\
\hline Plasmid & Relevant markers & \\
\hline pAB23BXN & Ap $p^{r} 2 \mu$ URA3 GAP promoter & T. Brake (Chiron Corporation, Emeryville, CA) \\
\hline pTRP & Ap $p^{r}$ TRP1 $2 \mu$ GAL promoter & Mulligan and Elledge (1994) \\
\hline pJA50 & $A p^{r} \mathrm{Kn}^{r} \mathrm{HIS} 3$ & Allen and Elledge (1994) \\
\hline pJA92 & Ap $p^{r}$ URA 3 CEN 4 RAD 53 & Allen et al. (1994) \\
\hline pSAD3-3B & Ap $p^{r}$ CEN 4 TRP1 MEC1 & this study \\
\hline pWJ87 & Ap ${ }^{r}$ CEN 4 TRP1 $\Delta$ mec1::HIS3 & this study \\
\hline pJR1267 & Ap $p^{r}$ URA3 orc2-1 & C. Fox and J. Rine (U niversity of California, Berkeley) \\
\hline pSE734 & $A p^{r}$ RNR3 & Elledge and Davis (1990) \\
\hline pSE757 & $A p^{r} 2 \mu$ TRP1 RNR 1 & Elledge and Davis (1990) \\
\hline pBAD40 & Ap $p^{r}$ CEN 4 URA3 & this study \\
\hline pBAD45 & Ap $p^{r}$ URA 3 CEN 4 MEC 1 & this study \\
\hline pBAD49 & Ap ${ }^{r}$ RNR1 PCR product & this study \\
\hline pBAD54 & Ap ${ }^{r}$ TRP1 $2 \mu$ GAP promoter & this study \\
\hline pBAD 58 & Ap $p^{r}$ RNR3 PCR product & this study \\
\hline pBAD 62 & $A p^{r}$ RNRI ORF & this study \\
\hline pBAD 70 & $A p^{r}$ TRP1 $2 \mu$ GAP-RNR1 & this study \\
\hline pBAD 74 & Ap $p^{r}$ RNR3 ORF & this study \\
\hline pBAD 79 & Ap $p^{r}$ TRP1 $2 \mu$ GAP-RNR3 & this study \\
\hline pBAD 114 & $A p^{r}$ TRP1 GAP-RNR1 & this study \\
\hline
\end{tabular}

\section{FACS analysis}

The amount of $250 \mu \mathrm{l}$ of cell culture $\left(\sim 1.5 \times 10^{6}\right.$ to $4 \times 10^{6}$ cells $)$ was added directly to $1 \mathrm{ml}$ of ethanol and allowed to stand $1 \mathrm{hr}$ for fixation. Cells were washed once with $70 \%$ ethanol and once with FACS buffer $(0.2 \mathrm{~m}$ Tris at pH 7.5, $20 \mathrm{~mm}$ EDTA). In a volume of $100 \mu \mathrm{l}$ of FACS buffer, cells were treated with 1 $\mathrm{mg} / \mathrm{ml} \mathrm{RN}$ ase $A$ at $37^{\circ} \mathrm{C}$ for $2 \mathrm{hr}$. Cells were then washed in PBS, treated with $5 \mu \mathrm{g} / \mathrm{ml}$ propidium iodide in a final volume of $1 \mathrm{ml}$ of PBS, and analyzed for fluorescence content using a Coulter model Epics XL-MCL. The DNA content of $\sim 30,000$ cells was determined for each sample. 


\section{PFGE of replication intermediates}

$\alpha$-Factor-arrested $\rho^{0}$ strains were released into YPD containing $0.2 \mathrm{M} \mathrm{HU}$ and $10 \mu \mathrm{g} / \mathrm{ml}$ nocodazole for $60 \mathrm{~min}$; cells were spun down, washed, and resuspended in YPD containing $10 \mu \mathrm{g} / \mathrm{ml}$ nocodazole. Cells from different time points during and after HU treatment were fixed in $70 \%$ ethanol overnight. These were subsequently resuspended in $0.5 \mathrm{M}$ EDTA, $1.2 \mathrm{~m}$ sorbitol, and 1 $\mathrm{M}$ Tris (pH 7.5). Chromosome plugs were prepared following a rapid two-step protocol without use of proteinase $K$ (Johnston 1994). Each $75 \mu \mathrm{l}$ plug contained $4.5 \times 10^{6}$ cells. PFGE was carried out in a Bio-Rad DR II apparatus for $24 \mathrm{hr}$, at $200 \mathrm{~V}$. Switching was done every $60 \mathrm{sec}$ for the first $15 \mathrm{hr}$, and every 90 sec for the last $9 \mathrm{hr}$. Chromosomes were visualized with ethidium bromide. The gel was photographed and chromosome band intensities were quantitated using N IH Image software.

\section{Strain and plasmid construction}

The source of the MEC1 gene was pSAD3-3B, which is a 9.5-kb fragment of the MEC1 genomic locus cloned into pRS414 (Sikorski and Hieter 1989). pBAD45 contains the 7.7-kb Sacl MEC1-containing fragment from pSAD3-3B cloned into the Sacl site of pBAD40, which is a derivative of pRS416 (Sikorski and Hieter 1989) deleted between the Notl and Sall sites. pBAD54 is a GAP promoter expression vector made by cloning the GAP expression cassette, containing the GAP promoter and GAP terminator flanking a multicloning site, as a BamHI fragment from pAB23BXN into the BamHI site of YEplac112 (Gietz and Sugino 1988).

The RNR1 and RNR3 ORFs were cloned by PCR and subcloned into pBS II KS( $\rightarrow$ to make pBAD49 and pBAD58. The ends of each ORF were sequenced to verify lack of mutation, and the central parts of each ORF were replaced by the corresponding fragment from a functional genomic clone. For RNR1 this was a BstEll-Xbal fragment from pSE757 generating pBAD 62, and for RNR3 it was a BstEll-HindllI fragment from pSE734 generating pBAD74. pBAD70 was made by subcloning the RNR1 ORF as a Xhol-Notl fragment from pBAD62 into Xhol-N otl-digested pBAD54. pBAD79 was made by subcloning the RNR3 ORF as a Psp1406I(T 4-filled in)-Notl fragment from pBAD 74 into pBAD 54 that had been cut with Xhol and T4-filled in and subsequently cut again with Notl.

The RAD53 gene knockout has been described previously (Allen et al. 1994). MEC 1 was knocked out by replacing a 7.5-kb BamHI fragment from pSAD3-3B with the BamHI fragment from pJA50 containing the HIS3 gene and a kanamycin resistance gene from Tn5 to form pWJ87. This removes all but the amino-terminal 33 amino acids from the MEC1 ORF. The 4.4$\mathrm{kb}$ Sacl fragment from pWJ87 containing the $\Delta$ mecl::HIS3 deletion construct was transformed into $Y 323$ to generate a diploid heterozygous for the mecl knockout Y 617.

The TRP1::GAP-RNR1 expression cassette was created by subcloning a Pstl-Sacl fragment from pBAD70 into Pstl-Sacldigested pRS404 to create pBAD114. rad53 and mecl null mutants suppressed by this GAP-RNR1 expression cassette were generated as follows. pBAD 114 was linearized within the TRP1 gene and transformed into $Y 312$ and $Y 617$ to create $Y 618$ and $Y 619$, and correct integration was confirmed by Southern blotting. $Y 618$ was sporulated and $Y 606$ and $Y 607$ were recovered. Y 619 was sporulated to obtain $Y 580$ and $Y 581$.

The temperature-sensitive orc2-1 mutant $Y 611$ was generated by looping the orc2-1 al lele from the U RA3-integrating plasmid pJR1267 into Y 300. We then selected transformants for 5-FOA resistance and screened them for temperature sensitivity. Y 612 was made by crossing Y 611 with $Y 620$ and sporulating and dis- secting the resulting diploid $Y 621$. Y 613, Y 614, Y 615, and Y 616 are four spores of identical genotype that were isolated from the diploid $Y 622$, which was in turn created by a mating between $Y 602$ and $Y C H 266$.

$Y 623$ and $Y 624, \mathrm{His}^{+} \rho^{0}$ derivatives of $Y 300$ and $Y 301$, respectively, were generated by serial culturing in minimal media containing ethidium bromide, as described in Fox et al. (1991).

\section{Acknowledgments}

We thank Ted Weinert, J. Diffley for sharing unpublished data, W. Shoeber for FACS analysis, B. Sclafani, C. Hardy, C. Fox, and J. Rine. We al so thank J. Diller for discussions, and members of the Elledge laboratory for comments, hel pful discussions, and/ or reagents. This work was supported by $\mathrm{N}$ ational Institutes of Health grant GM 44664 to S.J.E. S.J.E. is an investigator of the Howard Hughes Medical Institute.

The publication costs of this article were defrayed in part by payment of page charges. This article must therefore be hereby marked 'advertisement' in accordance with 18 USC section 1734 solely to indicate this fact.

\section{References}

Al-Khodairy, F., E. Fotou, K.S. Sheldrick, D.J.F. Griffiths, A.R. Lehmann, and A.M. Carr. 1994. Identification and characterization of new elements involved in checkpoint and feedback controls in fission yeast. Mol. Biol. Cell 5: 147-160.

Allen, J.B. and S.J. Elledge. 1994. A family of vectors that facilitate transposon and insertional mutagenesis of cloned genes in yeast. Yeast 10: 1267-1272.

Allen, J.B., Z. Zhou, W. Siede, E.C. Friedberg, and S.J. Elledge. 1994. The SAD1/RAD53 protein kinase controls multiple checkpoints and DNA damage-induced transcription in yeast. Genes \& Dev. 8: 2416-2428.

Barlow, C., S. Hirotsune, R. Paylor, M. Liyanage, M. Eckhaus, F. Collins, Y. Shiloh, J.N. Crawley, T. Ried, D. Tagle, and A. Wynshaw-Boris. 1996. Atm-deficient mice: A paradigm of ataxia tel angiectasia. Cell 86: 159-171.

Carr, A.M., M. Moudjou, N.J. Bentley, and I.M. Hagan. 1995. The chkl pathway is required to prevent mitosis following cell-cycle arrest at 'start'. Curr. Biol. 5: 1179-1190.

Elledge, S.J. 1996. Cell cycle checkpoints: preventing an identity crisis. Science 274: 1664-1672.

Elledge, S.J. and R.W. Davis. 1990. Two genes differentially regulated in the cell cycle and by DNA-damaging agents encode al ternative regulatory subunits of ribonucleotide reductase. Genes \& Dev. 4: 740-751.

Elledge, S.J., J. Mulligan, S. Ramer, M. Spottswood, and R.W. Davis. 1991. Lambda YES: A multifunctional cDN A expression vector for the isolation of genes by complementation of yeast and E. coli mutations. Proc. Natl. Acad. Sci. 88: 17311734.

Elledge, S.J., Z. Zhou, and J.B. Allen. 1992. Ribonucleotide reductase: Regulation, regulation, regulation. Trends Biochem. Sci. 17: 119-123.

Elson, A., Y. Wang, C.J. Daugherty, C.C. Morton, F. Zhou, J. Campos-Torres, and P. Leder. 1996. Pleiotropic defects in ataxia-telangiectasia protein-deficient mice. Proc. Natl. Acad. Sci. 93: 13084-13089.

Enoch, T., A. Carr, and P. N urse. 1992. Fission yeast genes involved in coupling mitosis to completion of DNA replication. Genes \& Dev. 6: 2035-2046.

Fersht, A.R. 1979. Fidelity of replication of phage phi $X 174$ DN A by DN A polymerase III holoenzyme: Spontaneous mu- 
tation by misincorporation. Proc. Natl. Acad. Sci. 76: 49464950.

Flaggs, G., A.W. Plug, K.M. Dunks, K.E. M undt, J.C. Ford, M.R. Quiggle, E.M. Taylor, C.H. Westphal, T. Ashley, M.F. Hoekstra, and A.M. Carr. 1997. Atm-dependent interactions of a mammalian chk1 homolog with meiotic chromosomes. Curr. Biol. 7: 977-986.

Ford, J.C., F. AI-Khodairy, E. Fotou, K.S. Sheldrick, D.J. Griffiths, and A.M. Carr. 1994. 14-3-3 protein homologs required for the DNA damage checkpoint in fission yeast. Science 265: 533-555.

Fox, T.D., L.S. Folley, J.J. Mulero, T.W. McMullin, P.E. Thorsness, L.O. Hedin, and M.C. Costanzo. 1991. Analysis and manipulation of yeast mitochondrial genes. Methods Enzymol. 194: 149-165.

Friedberg, E. C., G.C. Walker, and W. Siede. 1995. DNA repair and mutagenesis. ASM Press, Washington D.C.

Furnari, B., N. Rhind, and P. Russell. 1997. Cdc25 mitotic inducer targeted by chk1 DN A damage checkpoint kinase. Science 277: 1495-1497.

Gietz, R.D. and A. Sugino. 1988. New yeast-Escherichia coli shuttle vectors constructed with in vitro mutagenized yeast genes lacking six-base pair restriction sites. Gene 74: 527534.

Greenwell, P.W., S.L. Kronmal, S.E. Porter, J. Gassenhuber, B. Obermaier, and T.D. Petes. 1995. TEL1, a gene involved in controlling telomere length in S. cerevisiae, is homologous to the human ataxia tel angiectasia gene. Cell 82: 823-829.

Hennessy, K.M ., A. Lee, E. Chen, and D. Botstein. 1991. A group of interacting yeast DNA replication genes. Genes \& Dev. 5: 958-969.

Huang, M. and S.J. Elledge. 1997. Identification of RNR4, encoding a second essential small subunit of ribonucleotide reductase in Saccharomyces cerevisiae. Mol. Cell. Biol. 17: 6105-6113.

Jackson, A.L., P.M. Pahl, K. Harrison, J. Rosamond, and R.A. Sclafani. 1993. Cell cycle regulation of the yeast C dc7 protein kinase by association with the Dbf4 protein. Mol. Cell. Biol. 13: 2899-1908.

Johnston, J.R. 1994. Pulsed field gel el ectrophoresis. In Molecular genetics of yeast: A practical approach. (ed. J.R. Johnston), pp. 83-95. Oxford University Press, Oxford, UK.

Kaiser, C., S. Michaelis, and A. Mitchell. 1994. Methods in yeast genetics. Cold Spring Harbor Laboratory Press, Cold Spring Harbor, NY.

Kastan, M.B., Q. Zhan, W.S. El-Deiry, F. Carrier, T. Jacks, W.V. Walsh, B.S. Plunkett, B. Vogelstein, and A.J. Fournace, Jr. 1992. A mammalian cell cycle checkpoint pathway utilizing p53 and GADD45 is defective in Ataxia-Telangiectasia. Cell 71: 587-597.

Kato, R. and H. Ogawa. 1994. An essential gene, ESR1, is re quired for mitotic cell growth, DNA repair and meiotic re combination in Saccharomyces cerevisiae. Nucleic Acids Res. 22: 3104-3112.

Liang, C., M. Weinreich, and B. Stillman. 1995. ORC and Cdc6p interact and determine the frequency of initiation of DNA replication in the genome. Cell 81: 667-676.

Lindsay, H.D., D.J. Griffiths, R.J. Edwards, P.U. Christensen, J.M. Murray, F. Osman, N. Walworth, and A.M. Carr. 1998. S-phase-specific activation of Cdsl kinase defines a subpathway of the checkpoint response in Schizosaccharomyces pombe. Genes \& Dev. 12: 382-395.

Loeb, L.A. and T.A. Kunkel. 1982. Fidelity of DNA synthesis. Annu. Rev. Biochem. 51: 429-457.

Meyn, M.S. 1995. Ataxia-telangiectasia and cellular responses to DN A damage. Cancer Res. 55: 5991-6001.
M orrow, D.M., D.A. Tagle, Y. Shiloh, F.S. Collins, and P. Hieter. 1995. TEL1, an S. cerevisiae homolog of the human gene mutated in ataxia telangiectasia, is functionally related to the yeast checkpoint gene MEC1. Cell 82: 831-840.

Mulligan, J.T. and S.J. Elledge. 1994. The construction and use of CDNA libraries for genetic selections. In Molecular genetics of yeast: A practical approach (ed. J.R. Johnston), pp. 65-81. Oxford University Press, Oxford, UK.

Murakami, H. and H. Okayama. 1995. A kinase from fission yeast responsible for blocking mitosis in $\mathrm{S}$ phase. Nature 374: 817-819.

N avas, T.A., Z. Zhou, and S.J. Elledge. 1995. DNA polymerase $\epsilon$ links the DNA replicational machinery to the $S$ phase checkpoint. Cell 80: 29-39.

Pati, D., C. Keller, M. Groudine, and S.E. Plon. 1997. Reconstitution of a MEC1-independent checkpoint in yeast by expression of a novel human fork head CDNA. Mol. Cell Biol. 17: 3037-3046.

Peng, C.Y., P.R. Graves, R.S. Thoma, Z. Wu, A.S. Shaw, and H. Piwnica-Worms. 1997. Mitotic and G2 checkpoint control: regulation of 14-3-3 protein binding by phosphorylation of Cdc25C on serine-216. Science 277: 1501-1505.

Sanchez, Y., B.A. Desany, W. Jones, Q. Liu, B. Wang, and S.J. Elledge. 1996. Regulation of RAD53 by the ATM-like kinases MEC 1 and TEL1 in yeast cell cycle checkpoint pathways. Science 271: 357-360.

Sanchez, Y., C. Wong, R.S. Thomas, R. Richman, Z. Wu, H. Piwnica-Worms, and S.J. Elledge. 1997. Conservation of the Chk1 checkpoint pathway in mammals: Linkage of DNA damage to $\mathrm{Cdk}$ regulation through $\mathrm{Cdc} 25$. Science 277: 1497-1501.

Santocanale, S. and J.F.X. Diffley. 1998. A Mecl- and Rad53dependent checkpoint controls late-firing origins of DNA replication. Nature (in press).

Sikorski, R.S. and P. Hieter. 1989. A system of shuttle vectors and host strains designed for efficient manipulation of DN A in Saccharomyces cerevisiae. Genetics 122: 19-27.

Sun, Z., D.S. Fay, F. M arini, and D.F. Stern. 1996. Spk1/Rad53 is regulated by $\mathrm{Mecl}$-dependent protein phosphorylation in DNA replication and damage checkpoint pathways. Genes \& Dev. 10: 395-406.

Wal worth, N. and R. Bernards. 1996. rad-dependent response of the chk1-encoded protein kinase at the DN A damage checkpoint. Science 271: 353-356.

Wal worth, N., S. Davey, and D. Beach. 1993. Fission yeast chk1 protein kinase links the rad checkpoint pathway to cdc2. Nature 363: 368-371.

Weinert, T.A. and L.H. Hartwell. 1993. Cell cycle arrest of cdc mutants and specificity of the RADX9, checkpoint. Genetics 134: 63-80.

Weinert, T.A., G.L. Kiser, and L.H. Hartwell. 1994. Mitotic checkpoint genes in budding yeast and the dependence of mitosis on DNA replication and repair. Genes \& Dev. 8: $652-665$.

Xu, Y., T. Ashley, E.E. Brainerd, R.T. Bronson, M.S. Meyn, and D. Baltimore. 1996. Targeted disruption of ATM leads to growth retardation, chromosomal fragmentation during meiosis, immune defects, and thymic lymphoma. Genes \& Dev. 10: 2411-2422.

Zhou, Z. and S.J. Elledge. 1992. Isolation of crt mutants constitutive for transcription of the DNA damage inducible gene RNR3 in Saccharomyces cerevisiae. Genetics 131: 851-866.

- - - 1993. DU N 1 encodes a protein kinase that controls the DNA damage response in yeast. Cell 75: 1119-1127. 


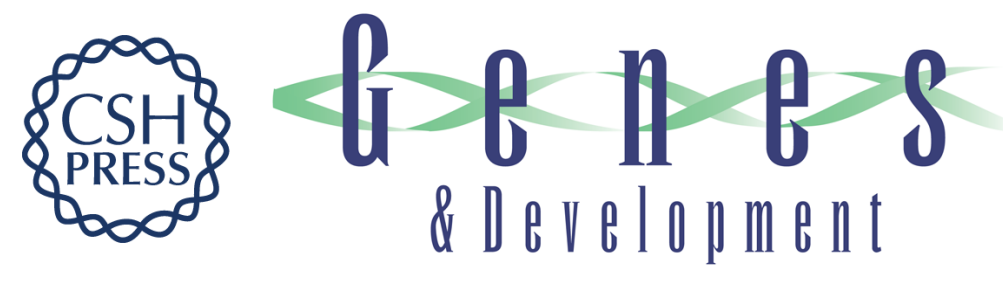

\section{Recovery from DNA replicational stress is the essential function of the S-phase checkpoint pathway}

Brian A. Desany, Annette A. Alcasabas, Jeffrey B. Bachant, et al.

Genes Dev. 1998, 12:

Access the most recent version at doi:10.1101/gad.12.18.2956

References This article cites 43 articles, 26 of which can be accessed free at: http://genesdev.cshlp.org/content/12/18/2956.full.html\#ref-list-1

License

Email Alerting Receive free email alerts when new articles cite this article - sign up in the box at the top Service right corner of the article or click here.

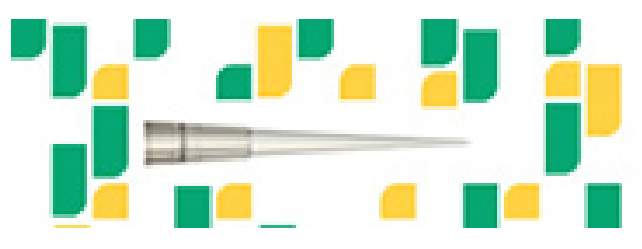

Focused on your science. 